\title{
The Important Role of Tumor Volume In Surgical Approach Choice, Surgical Complexity, and Post- Operative Complications In Renal Cell Carcinoma With Venous Tumor Thrombus From A Large Chinese Center Experience
}

\section{Qais A. Baheen}

Peking University Third Hospital

Zhuo Liu

Peking University Third Hospital

Yichang Hao

Peking University Third Hospital

Rejean R.R. Sawh

Peking University Third Hospital

Yuxuan Li

Peking University Third Hospital

Xun Zhao

Peking University Third Hospital

Lulin Ma ( $\square$ malulinpku@163.com)

Peking University Third Hospital

\section{Research Article}

Keywords: Tumor Thrombus, Tumor Volume, Complications, Prognosis

Posted Date: April 22nd, 2021

DOl: https://doi.org/10.21203/rs.3.rs-403174/v1

License: (c) (i) This work is licensed under a Creative Commons Attribution 4.0 International License.

Read Full License 


\section{Abstract}

Background: To evaluate the significance of interactions between tumor volume (TV) and surgical approach choice, surgical complexity, intra-operative blood loss, post-operative complications, as well as overall survival (OS) for patients with inferior vena cava tumor thrombus (IVCT-T) in locally advanced renal cell carcinoma (RCC).

Method: From Jan 2014 to Jan 2020, we identified 132 patients who underwent radical nephrectomy with inferior vena cava thrombectomy (RN-IVCT) in Peking University Third Hospital (PKUTH) and had available imaging for review. TV for RCC, renal vein (RV) and IVCT were separately measured through the well-known and commonly used application by medical professions $₫ 3 \mathrm{D}$ slicer. The significance of differences between groups was evaluated using linear regression. Prognostic factors were identified by univariate and multivariate analyses using the Cox proportional hazards model, and hazard ratios (HRs) with $95 \%$ confidence intervals were calculated.

Results: Patients were divided into three groups based on the inferior vena caval tumor thrombus volume (IVCT-TV); group 1 comprised of all patients with IVCT-TV between 0-15 cubic centimeter $\left(\mathrm{cm}^{3}\right)$, group 2 comprised of all patients with IVCT-TV between $15-30 \mathrm{~cm}^{3}$, and group 3 comprised of all patients with IVCT-TV greater than $30 \mathrm{~cm}^{3}$. Using these criteria, there were 48 patients in group 1, 38 in group 2, and 46 in group 3 , representing $36.6 \%, 28 \%$, and $35 \%$ of the total number of patients, respectively. There were 24 patients with Mayo grade I, 74 patients with Mayo grade II, 19 patients with Mayo grade III, and 18 patients with Mayo grade IV. Fifty-nine patients (44.7\%) underwent complete laparoscopic surgery, and 73 patients (55\%) underwent open surgery. The median surgery time was 334 minutes for group 1, 341 minutes for group 2 , and 374 minutes for group $3(p<0.044)$. The median intra-operative blood loss was $650 \mathrm{ml}$ for group $1,600 \mathrm{ml}$ for group 2, and $2350 \mathrm{ml}$ for Group 3 ( $\mathrm{p}<0.001)$. Post-operative complications occurred in $13(27.1 \%)$ patients from group 1, 15 (39.5\%) patients from group 2, and $35(76.1 \%)$ patients from group $3(p<0.001)$. Open approach surgery was the more desirable choice for caval tumor group $(p<0.001)$ and total thrombi volume group $(P<0.001)$. Overall surgery time was significantly longer, and operation was more difficult for renal venous thrombus volume group $(P<0.014)$, caval tumor volume group $(P<0.033)$, and total thrombi volume group $(P<0.005)$. Intra-operative blood loss was more and statistical difference was seen for caval tumor volume $(p<0.001)$ and total tumor volume $(p<0.001)$. No significant difference was noted for a demographic characteristic such as age, gender, side, size, BMI index, tumor type. Operative time, intra-operative blood loss, depth of IVC vascular wall invasion, surgical approach, and Mayo level were identified as the independent factors in this study.

Conclusion: Results of this present study indicate that a larger TV necessitates open surgery approach, and is associated with a prolonged operative time, increased intra-operative blood loss, increased surgical complexity, and a higher incidence of post-operative complications. However, TV does not affect the overall patient survival and hospitalization time.

\section{Introduction:}


Renal cell carcinoma (RCC) accounts for $3 \%-4 \%$ of all the gross tumors and has a tendency for invading the renal veins (RV) or inferior vena cava (IVC) in approximately $4-10 \%$ of patients ${ }^{1}$. Radical nephrectomy with inferior vena cava thrombectomy (RN-IVCT) is proven to be an effective treatment for RCC with inferior vena cava thrombus (IVCT $)^{2}$ and can improve patients' overall survival (OS), but this is one of the most complex procedures in urology with high rates of perioperative morbidity and mortality ${ }^{3,4}$. Furthermore, these patients have a higher risk of recurrence ${ }^{5}$.

The current Mayo classification is typically used for venous invasion in RCC. Level 0: the tumor thrombus is limited to the renal vein. Level I: tumor thrombus extends into the IVC wall at $<2 \mathrm{~cm}$ above the renal vein. Level II: The thrombus extends within the IVC $>2 \mathrm{~cm}$ above the renal vein but remains below the hepatic veins. Level III: Tumor thrombus which extends above the hepatic vein but below the diaphragm. Level IV: The thrombus extends above the diaphragm or into the right atrium ${ }^{3}$. This classification is beneficial, but it only takes into account the tumor height, which may be insufficient to evaluate the tumor's significance on the prognosis of these patients ${ }^{6,7}$ and help surgeons to more accurately assess the tumor size and risk of the operation.

A number of studies have been done for stratifications of patients with IVC, including tumor size, grade, stage, renal capsule invasion, adrenal involvement as well as lymph node, and distant metastasis ${ }^{8-10}$. However, the significance of tumor volume (TV) within the IVC has not been assessed in this setting ${ }^{11}$.

Therefore, the aim of this present study is to evaluate the surgical approach, surgical complexity, and the post-operative complications according to the volume of caval tumor and to help the physicians choose the better surgical approach, evaluate the complexity of the operation reasonably, effectively avoid the complications of the operation and pay more attention to the patients with higher post-operative risk.

\section{Materials And Method:}

\section{Patients:}

With Peking University Third Hospital (PKUTH) institutional review board approval, we search our database for 177 patients who underwent RN-IVCT and had available computed tomography enhanced (CT) imaging for review between Jan 2014 to Jan 2020. After excluding the patients that were not surgically treated, nephroblastoma, urothelial carcinoma, or other pathological types, patients without a pre-operative enhanced abdominal CT, and patients without a sufficient follow-up record, 132 patients were eligible for inclusion in the current study $\otimes$ Figure $1 \otimes$. The records of these 132 patients were retrospectively reviewed to evaluate the relevant clinical and pathological variables and survival.

\section{Tumor volume measurements:}

3D volume for all 132 patients in the present study was measured with the help of the latest edition of 3D Slicer. 3D Slicer is an open-source, free medical image processing software that runs smoothly on a personal computer and is compatible with multiple systems. 
Two urologists and a radiologist independently evaluated the boundary of tumor thrombus, enhancement of the IVC wall invasion, and overall tumor size from the coronal view of CT. With the help of 3D Slicer, for each axial slice, the cross-sectional area of RCC, RV thrombus, and the thrombus within the IVC were measured using the area measurement tool available in the software. This provided the area in cubic

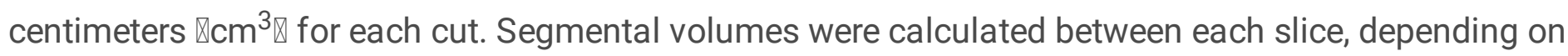
the thickness of each slice, which varied from 2 to $10 \mathrm{~mm}$ in length. These segmental volumes were added to calculate the total tumor thrombus volume.

Tumor volume was classified into groups. Volumes for renal cell carcinoma, renal vein thrombus, inferior vena cava, total thrombi volume, and total tumor volume are labeled as $A, B, C, D(D=B+C)$, and $E$ $(A+B+C)$, respectively, as shown in figure 2 .

\section{Follow-up}

Patients were evaluated for post-operative recurrence and general condition with abdominal CT or magnetic resonance imaging (MRI) every three months after the surgery and then every six months after that. Chest CT and brain MRI were used to detect metastasis. OS was calculated from the day of the surgery to the last follow-up date or date of death. Follow-up information was obtained from phone interviews and outpatient records. The median follow-up time was 30 months.

\section{Statistical analysis:}

All data are presented as mean $( \pm S D)$, with a range also provided for independent variables. Clinical data, including age, sex, side, body mass index, nuclear classification, serum hemoglobin, albumin, corrected serum calcium, alkaline phosphatase, serum creatinine, glomerular filtration rate, American Society of Anesthesiologists grading system score, renal sinus fat infiltration nodal, and metastasis status, and pathological features, were collected. Operative time, surgical complexity, intra-operative blood loss, IVC vascular wall invasion, thrombus level, surgical approach, and Mayo tumor thrombus classification level were analyzed according to the tumor volume. All statistical analyses were performed using the SPSS software package version 18. Continuous variables were tested for normality. One-Way ANOVA was used to compare the clinicopathological characteristics of the three groups of patients. For data of abnormal distribution, median (minimum, maximum) was used, the nonparametric test was used to compare the distribution differences between the three groups: the classification data were expressed by frequency (percentage), and chi-square test was used to compare the differences between the groups. Fishers' exact test was used for those who did not meet the chi-square test. Prognostic factors were identified by univariate and multivariate analyses using the Cox proportional hazards model, and hazard ratios (HRs) with $95 \%$ confidence intervals were calculated. A value of $\mathrm{P}<0.05$ was considered statistically significant.

\section{Result:}

Patient characteristics are shown in Table 1. All patients had tumor thrombi extending to RV and IVC, and underwent RN-IVCTT (36 left-sided and 96 right-sided). No significant difference was noted for 
demographic characteristics such as age, gender, side, size, BMI index, tumor type.

Patients were divided into three groups based on the IVCT-TV size. Group 1 comprised of all patients with IVCT-TV between 0-15 $\mathrm{cm}^{3}$, group 2 comprised of all patients with IVCT-TV between $15-30 \mathrm{~cm}^{3}$, and group 3 comprised of all patients with IVCT-TV greater than $30 \mathrm{~cm}^{3}$. Using these criteria, there were 48 patients in group 1, 38 in group 2, and 46 in group 3, representing $36.6 \%, 28 \%$, and $35 \%$ of the total number of patients, respectively.

Of all patients (132) studied, 59 patients (44.7\%) underwent complete laparoscopic surgery and 73 patients (55\%) underwent open surgery. Table 2 shows the surgical approach choice that was chosen for patients in the different groups. For patients with a larger caval tumor thrombus volume (C) and total tumor thrombus volume $(D)$ open surgery is a more often used surgical approach $(P<0.001)$. When a comparison of the surgical approach selected for the three groups is drawn, of 48 patients in group 1, 32 patients (66.7\%) underwent complete laparoscopic surgery, and 16 patients (33.3\%) underwent open surgery. Of the 38 patients in group 2, 19 patients (50\%) underwent laparoscopic surgery, and 19 patients $(50 \%)$ underwent open surgery. Of the total 46 patients in group 3, 8 patients $(17.6 \%)$ underwent laparoscopic surgery and 38 cases $(82.6 \%)$ underwent open surgery $(P<0.001)$.

Table 3 shows associations between TV and total operation time and overall surgical complexity. Results indicate that operation time was significantly longer for B (thrombus extending to renal vein, $P<0.014$ ), $C$ (thrombus extending to IVC, $P-<0.033$ ), and $D$ (thrombus extending to the renal vein and to the IVC, $P$ $<0.005)$. No significant difference was noted for $A(R C C)$ and $E(A+B+C)$. When a comparison of the total operation time for the three groups is drawn, total operation time was 334 minutes, 341 minutes, 374 minutes for groups 1,2 , and 3 , respectively. $(P<0.044)$ as shown in table 1.

The median intra-operative blood loss was $650 \mathrm{ml}, 600 \mathrm{ml}$, and $2350 \mathrm{ml}$ in groups 1, 2, and 3, respectively. As seen in table 4, intra-operative blood loss was significantly higher for $C$ and $D$, as shown in table 4 ( $P<$ 0.001). When compared the three groups, total blood loss for group $A$ was $650 \mathrm{ml}$ while for group $C$ was $2350 \mathrm{ml}(\mathrm{p}<0.001)$ as shown in table 1.

Post-operative complications were recorded in 63 patients. Of the 48 patients in group 1, 13 patients (27.1\%) had newly-occurred post-operative complications. Of the 38 patients in group 2, 15 patients (39.5\%) had post-operative complications. Of the 46 patients in group 3, 35 patients $(76.1 \%)$ had postoperative complications, as shown in table 1.

Fifty-eight patients were found to have tumors invading the vascular wall (Table 1). Statistical difference was seen after a comparison between the three groups was drawn $(P<0.005)$. In group 1,13 patients $(29.5 \%)$ were found to have tumors invading the vascular wall. That number rises to 19 (54.3\%) in group 2 and $26(63.4 \%)$ in group 3.

There were 24 patients with Mayo I, 74 patients with Mayo II, 19 patients with Mayo III, and 18 patients with Mayo IV, as shown in Table 1. The number of patients with Mayo I was 15 (31.3\%), 5 (13.2\%), and 4 
(8.7\%) for groups 1, 2, and 3, respectively. The number of patients with Mayo II was 28 (53.8\%), 25 (65.8\%), and 21 (45.7\%) for groups 1, 2, and 3, respectively. The number of patients with Mayo III was 3 (6.3\%), 4 (10.5\%), and $12(26.1 \%)$ for groups 1,2 , and 3, respectively. Lastly, the number of patients with Mayo IV was $2(4.2 \%), 7(10.5 \%)$, and $9(19.6 \%)$ for groups 1,2 , and 3 , respectively $(p<0.002)$, as shown in table 1.

There was no correlation between the volume of tumor thrombus and overall survival (Table 5区.

\section{Discussions:}

The aim of this present study is to evaluate the connections between TV and surgical approach choice, surgical complexity, and the post-operative complications for patients undergoing surgical resection of renal cell carcinoma with renal vein and inferior vena cava extension. We develop a 3D model using 3D Slicer to separately calculate the volumes for RCC, RV, and IVC. Two urologists and a radiologist independently evaluated the margins of tumor thrombus, enhancement of the IVC wall invasion, and overall tumor size in the coronal plane using coronal view CT (Figure 3.). Segmental volumes were calculated according to the thickness of each slice which varied from 2 to $10 \mathrm{~mm}$ in length (Figure 4.). These segmental volumes were added to calculate the total tumor thrombus volume. The average time spent for tumor volume measurement (RCC-TV+RVT-TV+IVC-TV) was 30 minutes, and the total time spent was 3960 minutes.

3D slicer is a free and open-source 3D visualization medical image processing and information analysis software. This application was first created by David Gering in 1999 and was developed by the National Institutes of Health and the global developer community ${ }^{12,13}$. It has a history of more than 20 years and is still being updated. The latest version introduces nearly 1000 enhancements and bug fixes for better performance and stability. This software has been used and cited in more than 443 publications and more than 36 pulmonary-specific articles ${ }^{14}$. And to the best of our knowledge, the present study is the first to perform a 3D volume measurement for patients with inferior vena cava tumor thrombus in locally advanced renal cell carcinoma.

In this study, the first significance of tumor thrombus volume lies in its association with the choice of surgical approach. It is well known that surgical resection is the best treatment option for patients with locally advanced renal cell carcinoma ${ }^{2}$, but very little is known about the best surgical approach, and studies on this particular aspect are limited. An incorrect surgical approach is associated with an increased incidence of intra and post-operative complications, so it is of cardinal importance that an ideal surgical approach is selected for every patient. This study found that there was a reduction in the number of patients that underwent laparoscopic surgery when the tumor thrombus volume was greater than 30 $\mathrm{cm}^{3}$. Even in those few cases where laparoscopic surgery was attempted, the chances of converting to open surgery were high. Although a number of studies have attempted to establish an association between the tumor size and the choice of surgical approach, the significance of the tumor volume has barely been studied. Lardas M reports that tumor thrombectomy for grade III and IV tumors is difficult to 
perform laparoscopically because the upper edge of the tumor thrombus has reached or already exceeds the hepatic vein ${ }^{2}$. However, this could also depend on the surgeon's experience, preference, patientspecific anatomy, and tumor thrombus extent. Therefore, the results of this study could help surgeons choose a better surgical approach and inform patients pre-operatively about the best surgical approach and possible complications.

The second significance of tumor volume lies in the observance that patients with larger caval tumor volumes were associated with more intra-operative blood loss when compared to patients with smaller caval tumor volumes. The total blood loss for group 1 was $650 \mathrm{ml}$, while that for group 3 was $2350 \mathrm{ml}$. However, for group 2, the median blood loss was $600 \mathrm{ml}$. This could be because of the limited number of patients in group 2 that were used in this study (48 vs. 38 vs. 46 for groups 1, 2, and 3, respectively). A similar study conducted by Kamran et al. arrived at a similar result ${ }^{11}$. A number of techniques, including gonadal vein stump, posterior dissection of the inferior vena cava, and segmentation of the lumbar vein and renal artery to allow a greater activity of the inferior vena cava to help identify previously missing gonadal veins, as well as embolization of the renal artery, can be used to reduce the intra-operative blood loss. However, intra-operative blood loss also very much depends on the surgeon's experience and the patient's general condition. To reduce post-operative complications caused by intra-operative blood loss for patients with a large caval tumor $\left(>30 \mathrm{~cm}^{3}\right)$, sufficient blood should be prepared pre-operatively.

In total, 63 patients developed post-operative complications. As can be expected, a higher incidence of post-operative complications was observed in patients with a larger tumor volume. The results can help surgeons pre-optatively evaluate the choice of surgical approach, possible complications, and how to sufficiently manage such complications should they actually arise. For high-risk groups, an intensive care unit (ICU) ward should be prepared, and patients should be pre-operatively informed about such complications associated with open surgery as pain, etc.

Other important factors associated with tumor volume were IVC vascular wall invasion, tumor diameter, and Mayo level. The importance of tumor diameter on the outcome of patients was previously studied in our center ${ }^{15,16}$. One of the most controversial topics is the importance and usages of Mayo classification. Although the Mayo classification is particularly useful when it comes to surgical techniques, the importance of tumor diameter is barely taken into consideration which can be insufficient to intraoperatively evaluate the prognosis of these patients. In our study, we found that there are several patients with a Mayo I grade, but with a large tumor volume, this is because a wide tumor can also cause a prolonged operative time, increased surgical complexity, more intra-operative blood loss, and postoperative complications. Therefore, for such patients with a low Mayo grade tumor yet a wide in size tumors, similar measurements should be taken pre-operatively.

In this study, there was no association between tumor volume and overall survival. A previous study about esophageal cancer conducted by Créhange et al. reports that $100 \mathrm{~cm}^{3}$ was the optimal cut-off value to distinguish $0 S^{17}$. On the other hand, Karma et al. reported that tumor volume $>15 \mathrm{~cm}^{3}$ is associated with $\mathrm{OS}^{11}$ for RCC patients with caval tumor thrombus. Chen et al.'s research on tumor volume 
association with esophageal cancer results shows that the cut-off value of tumor volume was $20 \mathrm{~cm}^{3}, 18$. Further studies with a larger number are required to clarify the association between tumor volume and overall survival for RCC patients with caval tumor thrombus.

This study had several limitations. All patients were surgically treated in the same hospital. Therefore, similar techniques were used. Although two experienced urologists and a radiologist measured the tumor volume, it may still not be as accurate as if the tumor volume was automatically measured by a developed software to detect TV. However, an advantage of this study its larger number compared to previous studies, the comparisons between three groups of patients, and identifying the importance of tumor volume on surgical approach choice, intra-operative blood loss, and post-operative complications. Randomized trials with a larger number of patients from different institutions are necessary to clarify the importance of tumor volume in RCC patients with caval tumor thrombus. Software to automatically detect and measure tumor volume should be developed to help surgeons choose a better surgical approach, pre-operatively inform patients about possible complications and reduce blood loss and postoperative complications for high-risk patients.

\section{Conclusion:}

Our result shows that a larger tumor volume necessitates open surgery, and is associated with prolonged operative time, increased intra-operative blood loss, increased surgical complexity, and a higher incidence of post-operative complications. However, there was no association between tumor volume and overall survival. Randomized trials with larger numbers of patients from different institutions are necessary to clarify the importance of tumor volume in RCC patients with caval tumor thrombus. For the next step, software or program within the imaging machines should be developed to automatically detect and more actuarily measure tumor volume.

\section{Abbreviations}

TV: Tumor Volume, OS: Overall Survival, IVCT-T: Inferior Vena Cava Tumor Thrombus,

RCC: Renal Cell Carcinoma, RN-IVCT: Radical Nephrectomy And Inferior Vena Cava Thrombectomy, PKUTH: Peking University Third Hospital, RV: Renal Vein, CT: Computed Tomography, MRI: Magnetic Resonance Imaging, $\mathrm{Cm}^{3}$ : Cubic Centimeters, HRs: Hazard Ratios, ICU: Intensive Care Unit

\section{Declarations}

\section{Data availability statement}

The datasets used and/or analysed during the current study are available from the corresponding author on reasonable request

\section{Ethics declarations}


This study was approved by the Ethics committee of Peking University Third Hospital and all methods were performed in accordance with the principles of latest version of the Declaration of Helsinki. Signed and dated informed consent was obtained from all subjects or, if subjects are under 16 , from a parent and/or legal guardian.

\section{Consent for publication}

Not applicable.

\section{Acknowledgments:}

We thank Jinghan Dong for providing follow-up data.

\section{Funding:}

Not applicable.

\section{Contributions:}

QAB, ZL, YCH contributed as the first authors of this study. QAB and RRRS measured the tumor volume using 3D Slicer and made figures. YXL analyzed the statistical data. XZ provided the clinical imaging data. LLM made the revision. All authors contributed to the design of this project, data collections, and literature review. All authors have read and approved the final submitted manuscript.

\section{Competing interests:}

The authors declare that they have no competing interests.

\section{References}

1. Wang B, Li H, Ma X, et al. Robot-assisted laparoscopic inferior vena cava thrombectomy: different sides require different techniques. Eur Urol. 2016;69(6):1112-1119.

2. Lardas M, Stewart F, Scrimgeour D, et al. Systematic review of surgical management of nonmetastatic renal cell carcinoma with vena caval thrombus. Eur Urol. 2016;70(2):265-280.

3. Haddad AQ, Leibovich BC, Abel EJ, et al. Pre-operative multivariable prognostic models for prediction of survival and major complications following surgical resection of renal cell carcinoma with suprahepatic caval tumor thrombus. In: Urologic Oncology: Seminars and Original Investigations. Vol 33. Elsevier; 2015:388-e1.

4. Toren P, Abouassaly R, Timilshina N, Kulkarni G, Alibhai S, Finelli A. Results of a national populationbased study of outcomes of surgery for renal tumors associated with inferior vena cava thrombus. Urology. 2013;82(3):572-578.

5. Haddad AQ, Wood CG, Abel EJ, et al. Oncologic outcomes following surgical resection of renal cell carcinoma with inferior vena caval thrombus extending above the hepatic veins: a contemporary 
multicenter cohort. J Urol. 2014;192(4):1050-1056.

6. Liu Z, Li L, Hong P, et al. A Predictive Model for Tumor Invasion of the Inferior Vena Cava Wall Using Multimodal Imaging in Patients with Renal Cell Carcinoma and Inferior Vena Cava Tumor Thrombus. Biomed Res Int. 2020;2020.

7. Quencer KB, Friedman T, Sheth R, Oklu R. Tumor thrombus: incidence, imaging, prognosis and treatment. Cardiovasc Diagn Ther. 2017;7(Suppl 3):S165.

8. Miyake H, Terakawa T, Furukawa J, Muramaki M, Fujisawa M. Prognostic significance of tumor extension into venous system in patients undergoing surgical treatment for renal cell carcinoma with venous tumor thrombus. Eur J Surg Oncol. 2012;38(7):630-636.

9. Blute ML, Leibovich BC, Lohse CM, Cheville JC, Zincke H. The Mayo Clinic experience with surgical management, complications, and outcome for patients with renal cell carcinoma and venous tumour thrombus. BJU Int. 2004;94(1):33-41.

10. Lambert EH, Pierorazio PM, Shabsigh A, Olsson CA, Benson MC, McKiernan JM. Prognostic risk stratification and clinical outcomes in patients undergoing surgical treatment for renal cell carcinoma with vascular tumor thrombus. Urology. 2007;69(6):1054-1058.

11. Zargar-Shoshtari K, Sharma P, Espiritu P, et al. Caval tumor thrombus volume influences outcomes in renal cell carcinoma with venous extension. In: Urologic Oncology: Seminars and Original Investigations. Vol 33. Elsevier; 2015:112-e23.

12. Gering DT. A system for surgical planning and guidance using image fusion and interventional MR. Published online 1999.

13. Cheng GZ, Estepar RSJ, Folch E, Onieva J, Gangadharan S, Majid A. Three-dimensional printing and 3D slicer: powerful tools in understanding and treating structural lung disease. Chest. 2016;149(5):1136-1142.

14. Liu Z, Zhao X, Zhang H-X, et al. Surgical complexity and prognostic outcome of small volume renal cell carcinoma with high-level venous tumor thrombus and large volume renal cell carcinoma with low-level thrombus. Chin Med J (Engl). 2019;132(15):1780.

15. Zhao X, Liu Z, Zhang H, et al. PKUTHLP score: A comprehensive system to predict surgical approach in radical nephrectomy and thrombectomy. Oncol Lett. 2020;20(1):201-208.

16. Créhange $G$, Bosset $M$, Fabrice $L$, et al. Tumor volume as outcome determinant in patients treated with chemoradiation for locally advanced esophageal cancer. Am J Clin Oncol. 2006;29(6):583-587.

17. Chen C-Z, Chen J-Z, Li D-R, et al. Long-term outcomes and prognostic factors for patients with esophageal cancer following radiotherapy. World J Gastroenterol WJG. 2013;19(10):1639.

18. Wagner B, Patard J-J, Méjean A, et al. Prognostic value of renal vein and inferior vena cava involvement in renal cell carcinoma. Eur Urol. 2009;55(2):452-460.

\section{Tables}


Table 1

Clinical and pathological characteristics of 132 patients with inferior vena cava tumor thrombus(IVCT-T) in locally advanced renal cell carcinoma (RCC) and subgroup comparison of variables according to the tumor volume.

\begin{tabular}{|c|c|c|c|c|c|}
\hline & $\mathbf{n}$ & Group1 & Group2 & Group3 & $\mathbf{p}$ \\
\hline $\begin{array}{l}\text { Sex, n (\%) } \\
\text { Male } \\
\text { Female }\end{array}$ & 132 & $\begin{array}{l}31(64.6) \\
17(35.4)\end{array}$ & $\begin{array}{l}30(78.9) \\
8(21.1)\end{array}$ & $\begin{array}{l}39(84.8) \\
7(24.2)\end{array}$ & 0.063 \\
\hline Age, y, mean \pm SD & 132 & $59.13 \pm 9.795$ & $62.05 \pm 10.77$ & $\begin{array}{l}58.30 \pm \\
8.167\end{array}$ & 0.182 \\
\hline $\begin{array}{l}\text { BMI, kg/ } \\
\text { median (min, max) }\end{array}$ & 132 & $\begin{array}{l}22.40(16.36 \\
32.89)\end{array}$ & $\begin{array}{l}23.37(17.93 \\
33.03)\end{array}$ & $\begin{array}{l}24.8(15.23, \\
33.03)\end{array}$ & 0.054 \\
\hline $\begin{array}{l}\text { Side, n (\%) } \\
\text { Left } \\
\text { Right }\end{array}$ & 132 & $\begin{array}{l}16(33.3) \\
32(66.7)\end{array}$ & $\begin{array}{l}9(23.7) \\
29(76.3)\end{array}$ & $\begin{array}{l}11(23.9) \\
35(76.1)\end{array}$ & 0.497 \\
\hline $\begin{array}{l}\text { ASA grade, } n(\%) \\
1 \\
2 \\
3\end{array}$ & 132 & $\begin{array}{l}2(4.2) \\
41(85.4) \\
5(10.4)\end{array}$ & $\begin{array}{l}4(10.5) \\
30(78.9) \\
4(10.5)\end{array}$ & $\begin{array}{l}1(2.2) \\
35(76.1) \\
10(21.7)\end{array}$ & 0.212 \\
\hline $\begin{array}{l}\text { Nuclear classification, } \mathrm{n}(\%) \\
1 \\
2 \\
3 \\
4\end{array}$ & 129 & $\begin{array}{l}0(0) \\
21(44.7) \\
17(36.2) \\
9(19.1)\end{array}$ & $\begin{array}{l}2(5.4) \\
12(32.4) \\
11(29.7) \\
12(32.4)\end{array}$ & $\begin{array}{l}0(0) \\
13(28.9) \\
20(44.4) \\
12(26.7)\end{array}$ & 0.153 \\
\hline $\begin{array}{l}\text { Clinical symptoms, } \mathrm{n}(\%) \\
\text { No clinical symptoms } \\
\text { Local symptoms } \\
\text { Systemic symptoms } \\
\text { Both }\end{array}$ & 132 & $\begin{array}{l}9(18.8) \\
22(45.8) \\
7(14.6) \\
10(20.8)\end{array}$ & $\begin{array}{l}3(7.9) \\
24(63.2) \\
4(10.5) \\
7(18.4)\end{array}$ & $\begin{array}{l}7(15.2) \\
26(56.5) \\
4(8.7) \\
9(19.6)\end{array}$ & 0.704 \\
\hline $\begin{array}{l}\text { White blood cell, median (min, } \\
\text { max) }\end{array}$ & 132 & $6.43(3,24)$ & $6.62(2,13)$ & $6.34(3,9)$ & 0.601 \\
\hline Red blood cell, median (min, max) & 132 & $4.26(1,6)$ & $4.21(3,5)$ & $4.16(2,7)$ & 0.799 \\
\hline Hemoglobin, $g / L$, mean $\pm S D$ & 132 & $\begin{array}{l}119.35 \pm \\
25.40\end{array}$ & $\begin{array}{l}115.89 \pm \\
18.65\end{array}$ & $\begin{array}{l}115.07 \pm \\
23.28\end{array}$ & 0.632 \\
\hline $\begin{array}{l}\text { Platelet count, } \\
\text {,median (min, max) }\end{array}$ & 132 & $246(90,544)$ & $\begin{array}{l}246.5(67 \\
689)\end{array}$ & $\begin{array}{l}221.5(69 \\
568)\end{array}$ & 0.464 \\
\hline Lymphocytes, mean \pm SD & 132 & $1.32 \pm 0.56$ & $1.29 \pm 0.41$ & $1.20 \pm 0.40$ & 0.431 \\
\hline Neutrophils, median (min, max) & 132 & $4.25(3,22)$ & $4.98(1,11)$ & $6.21(2,85)$ & 0.894 \\
\hline Monocytes, median (min, max) & 132 & $0.40(0,1)$ & $0.44(0,1)$ & $0.46(0,1)$ & 0.278 \\
\hline
\end{tabular}




\begin{tabular}{|c|c|c|c|c|c|}
\hline & $\mathbf{n}$ & Group1 & Group2 & Group3 & $\mathbf{p}$ \\
\hline Albumin, median (min, max) & 132 & $38.7(19,48)$ & $39.05(25,51)$ & $38.1(21,47)$ & 0.850 \\
\hline $\begin{array}{l}\text { Blood urea nitrogen, median (min, } \\
\text { max) }\end{array}$ & 132 & $6.25(3,10)$ & $5.65(3,8)$ & $6.45(3,30)$ & 0.167 \\
\hline ALT, median (min, max) & 132 & $17(5,57)$ & $15(7,302)$ & $17(6,78)$ & 0.700 \\
\hline AST, median (min, max) & 132 & $16(9,54)$ & $19(10,226)$ & $19(10,115)$ & 0.308 \\
\hline Creatinine, median (min, max) & 132 & $2.29(1,3)$ & $2.3(2,89)$ & $2.26(2,3)$ & 0.693 \\
\hline $\begin{array}{l}\text { Alkaline Phosphatase, } \mathrm{U} / \mathrm{L} \text {, } \\
\text { median (min, } \max \text { ) }\end{array}$ & 132 & $80(52,846)$ & $79.5(45,264)$ & $\begin{array}{l}94.5(29 \\
287)\end{array}$ & 0.205 \\
\hline $\begin{array}{l}\text { Lymph node metastasis, n (\%) } \\
\text { No } \\
\text { Yes }\end{array}$ & 132 & $\begin{array}{l}17(35.4) \\
31(64.6)\end{array}$ & $\begin{array}{l}15(39.5) \\
23(60.5)\end{array}$ & $\begin{array}{l}14(30.4) \\
32(69.6)\end{array}$ & 0.684 \\
\hline $\begin{array}{l}\text { Adrenal metastasis, } \mathrm{n}(\%) \\
\text { No } \\
\text { Yes }\end{array}$ & 132 & $\begin{array}{l}45(93.8) \\
3(6.3)\end{array}$ & $\begin{array}{l}32(84.2) \\
6(15.8)\end{array}$ & $\begin{array}{l}41(89.1) \\
5(10.9)\end{array}$ & 0.360 \\
\hline $\begin{array}{l}\text { Distant metastasis, n (\%) } \\
\text { No } \\
\text { Yes }\end{array}$ & 132 & $\begin{array}{l}33(68.8) \\
15(31.3)\end{array}$ & $\begin{array}{l}26(68.4) \\
12(31.6)\end{array}$ & $\begin{array}{l}32(69.6) \\
14(30.4)\end{array}$ & 0.993 \\
\hline $\begin{array}{l}\text { Complicated with thrombosis, } \mathrm{n} \\
(\%) \\
\text { No } \\
\text { Yes }\end{array}$ & 132 & $\begin{array}{l}38(79.2) \\
10(20.8)\end{array}$ & $\begin{array}{l}31(91.6) \\
7(18.4)\end{array}$ & $\begin{array}{l}28(60.9) \\
18(39.1)\end{array}$ & 0.054 \\
\hline $\begin{array}{l}\text { Necrosis, n (\%) } \\
\text { No } \\
\text { Yes }\end{array}$ & 132 & $\begin{array}{l}23(47.9) \\
25(25.1)\end{array}$ & $\begin{array}{l}23(60.5) \\
15(39.5)\end{array}$ & $\begin{array}{l}24(52.2) \\
22(47.8)\end{array}$ & 0.503 \\
\hline $\begin{array}{l}\text { Invasion of renal pelvis and calyx, } \\
n(\%) \\
\text { No } \\
\text { Yes }\end{array}$ & 132 & $\begin{array}{l}40(83.3) \\
8(16.7)\end{array}$ & $\begin{array}{l}28(73.7) \\
10(26.3)\end{array}$ & $\begin{array}{l}37(80.4) \\
9(19.6)\end{array}$ & 0.536 \\
\hline $\begin{array}{l}\text { Renal sinus fat infiltration, } \mathrm{n}(\%) \\
\text { No } \\
\text { Yes }\end{array}$ & 130 & $\begin{array}{l}41(89.1) \\
5(10.9)\end{array}$ & $\begin{array}{l}34(89.5) \\
4(10.5)\end{array}$ & $\begin{array}{l}40(87.0) \\
6(13.0)\end{array}$ & 0.923 \\
\hline $\begin{array}{l}\text { Perirenal fat infiltration, } \mathrm{n}(\%) \\
\text { No } \\
\text { Yes }\end{array}$ & 132 & $\begin{array}{l}37(77.1) \\
11(22.9)\end{array}$ & $\begin{array}{l}25(65.8) \\
13(34.2)\end{array}$ & $\begin{array}{l}29(63.0) \\
17(37.0)\end{array}$ & 0.300 \\
\hline $\begin{array}{l}\text { Pathology type, } n(\%) \\
\text { Clear cell RCC } \\
\text { Non-clear cell RCC }\end{array}$ & 132 & $\begin{array}{l}40(83.3) \\
8(16.7)\end{array}$ & $\begin{array}{l}28(7.7) \\
10(26.3)\end{array}$ & $\begin{array}{l}38(82.6) \\
8(17.4)\end{array}$ & 0.476 \\
\hline $\begin{array}{l}\text { Sarcomatoid differentiation, } \mathrm{n}(\%) \\
\text { No } \\
\text { Yes }\end{array}$ & 132 & $\begin{array}{l}40(83.3) \\
8(16.7)\end{array}$ & $\begin{array}{l}34(89.5) \\
4(10.5)\end{array}$ & $\begin{array}{l}36(78.3) \\
10(21.7)\end{array}$ & 0.390 \\
\hline
\end{tabular}




\begin{tabular}{|c|c|c|c|c|c|}
\hline & $\mathbf{n}$ & Group1 & Group2 & Group3 & $\mathbf{p}$ \\
\hline $\begin{array}{l}\text { Surgical approach, n (\%) } \\
\text { Laparoscopic Surgery } \\
\text { Open Surgery }\end{array}$ & 132 & $\begin{array}{l}32(66.7) \\
16(33.3)\end{array}$ & $\begin{array}{l}19(50.0) \\
19(50.0)\end{array}$ & $\begin{array}{l}8(17.4) \\
38(82.6)\end{array}$ & 0.001 \\
\hline $\begin{array}{l}\text { Mayo classification, n (\%) } \\
\text { II } \\
\text { III } \\
\text { IV }\end{array}$ & 132 & $\begin{array}{l}15(31.3) \\
28(53.8) \\
3(6.3) \\
2(4.2)\end{array}$ & $\begin{array}{l}5(13.2) \\
25(65.8) \\
4(10.5) \\
7(10.5)\end{array}$ & $\begin{array}{l}4(8.7) \\
21(45.7) \\
12(26.1) \\
9(19.6)\end{array}$ & 0.002 \\
\hline $\begin{array}{l}\text { Operative time, min, median (min, } \\
\max \text { ) }\end{array}$ & 129 & $\begin{array}{l}334(165 \\
589)\end{array}$ & $\begin{array}{l}341.5(161 \\
796)\end{array}$ & $\begin{array}{l}374(219 \\
873)\end{array}$ & 0.044 \\
\hline $\begin{array}{l}\text { Surgical blood loss, } \mathrm{mL} \text {, median } \\
\text { (min, max) }\end{array}$ & 132 & $\begin{array}{l}650(20 \\
4500)\end{array}$ & $\begin{array}{l}600(20 \\
4700)\end{array}$ & $\begin{array}{l}2350(0 \\
8800)\end{array}$ & 0.000 \\
\hline $\begin{array}{l}\text { Postoperative hospital stay, } \\
\text { median (min, max) }\end{array}$ & 132 & $8(4,34)$ & $9(4,61)$ & $10(4,70)$ & 0.089 \\
\hline IVC maximum width, mean \pm SD & 132 & $2.44 \pm 0.88$ & $2.96 \pm 0.80$ & $3.46 \pm 0.88$ & 0.000 \\
\hline $\begin{array}{l}\text { Vascular wall adhesion, } \mathrm{n}(\%) \\
\text { No } \\
\text { Yes }\end{array}$ & 120 & $\begin{array}{l}31(70.5) \\
13(29.5)\end{array}$ & $\begin{array}{l}16(45.7) \\
19(54.3)\end{array}$ & $\begin{array}{l}15(36.6) \\
26(63.4)\end{array}$ & 0.005 \\
\hline $\begin{array}{l}\text { Postoperative complication, } \mathrm{n}(\%) \\
\text { No } \\
\text { Yes }\end{array}$ & 132 & $\begin{array}{l}35(72.9) \\
13(27.1)\end{array}$ & $\begin{array}{l}23(60.5) \\
15(39.5)\end{array}$ & $\begin{array}{l}11(23.9) \\
35(76.1)\end{array}$ & 0.001 \\
\hline
\end{tabular}

Table 2

Surgical approach choice

\begin{tabular}{|c|c|c|c|c|}
\hline & $\mathbf{n}$ & Laparoscopic surgery & Open surgery & $\mathbf{p}$ \\
\hline A,median ( $\min \square \max$ ) & 132 & $216.9(22.0,639.1)$ & 236.71(7.66.1532.1) & 0.332 \\
\hline B,median ( $\min \square \max$ ) & 132 & $9.1(1.9,35.6)$ & $9.6(1.42,39)$ & 0.741 \\
\hline C ,median ( min,max) & 132 & $14.6(2.9,46.2)$ & $32.26(3.6,103.41)$ & 0.001 \\
\hline$A+B+C$, median $(\min , \max )$ & 132 & $254.58(48.8,678.1)$ & $280.71(25.76,1558.860)$ & 0.141 \\
\hline $\mathrm{D}$, median ( min,max) & 132 & $27.4(7.3,65.6)$ & $43.5(7.5,114.027)$ & 0.001 \\
\hline
\end{tabular}


Table 3

Tumor volume and operative time and surgical complexity

\begin{tabular}{|llll|}
\hline & $\mathbf{p}$ & $\mathbf{B}(95 \% \mathrm{Cl})$ & Beta \\
\hline $\mathrm{RCC} \mathrm{cm3} \mathrm{(A)}$ & 0.799 & $-0.009(-0.083,0.064)$ & -0.023 \\
$\mathrm{RV} \mathrm{cm3}(\mathrm{B})$ & 0.014 & $3.362(0.693-6.031)$ & 0.216 \\
\hline $\mathrm{V} C \mathrm{~cm} 3(\mathrm{C})$ & 0.033 & $1.167(0.094-2.239)$ & 0.188 \\
\hline $\mathrm{A}+\mathrm{B}+\mathrm{C}$ & 0.962 & $-0.002(-0.074-0.070)$ & -0.004 \\
\hline $\mathrm{D}=\mathrm{B}+\mathrm{C}$ & 0.005 & $1.373(0.422-2.323)$ & 0.246 \\
\hline
\end{tabular}

Table 4

Intra-operative blood Loss

\begin{tabular}{|llll|}
\hline & p & B(95\%Cl) & Beta \\
\hline$R C C ~ ~^{3} A$ & 0.142 & $0.757(-0.258,1.772)$ & 0.128 \\
\hline$R V c^{3}(B)$ & 0.434 & $14.473(-22.027-50.974)$ & 0.069 \\
\hline $\mathrm{IVC} \mathrm{cm}{ }^{3}(C)$ & 0.001 & $32.185(18.847-45.523)$ & 0.386 \\
\hline$A+B+C$ & 0.075 & $0.904(-0.093-1.901)$ & 0.155 \\
\hline$D=B+C$ & 0.001 & $27.317(15.346-39.293)$ & 0.368 \\
\hline
\end{tabular}

Table 5

Tumor volume does not affect patient's

prognosis.

\begin{tabular}{|lll|}
\hline & p & HR(95\%Cl) \\
\hline $\mathrm{D}=\mathrm{B}+\mathrm{C}$ & 0.415 & $0.994(0.978-1.009)$ \\
\hline $\mathrm{RV} \mathrm{cm3}(\mathrm{B})$ & 0.866 & $0.996(0.956-1.038)$ \\
\hline $\mathrm{IVC} \mathrm{cm3} \mathrm{(C)}$ & 0.387 & $0.992(0.974-1.010)$ \\
\hline $\mathrm{A}+\mathrm{B}+\mathrm{C}$ & 0.226 & $1.001(1.000-1.002)$ \\
\hline
\end{tabular}






Figure 1

Flow chart of this study. The important role of tumor volume in surgical approach choice, surgical complexity, and post-operative complications in renal cell carcinoma with venous tumor thrombus from a large Chinese center experience 


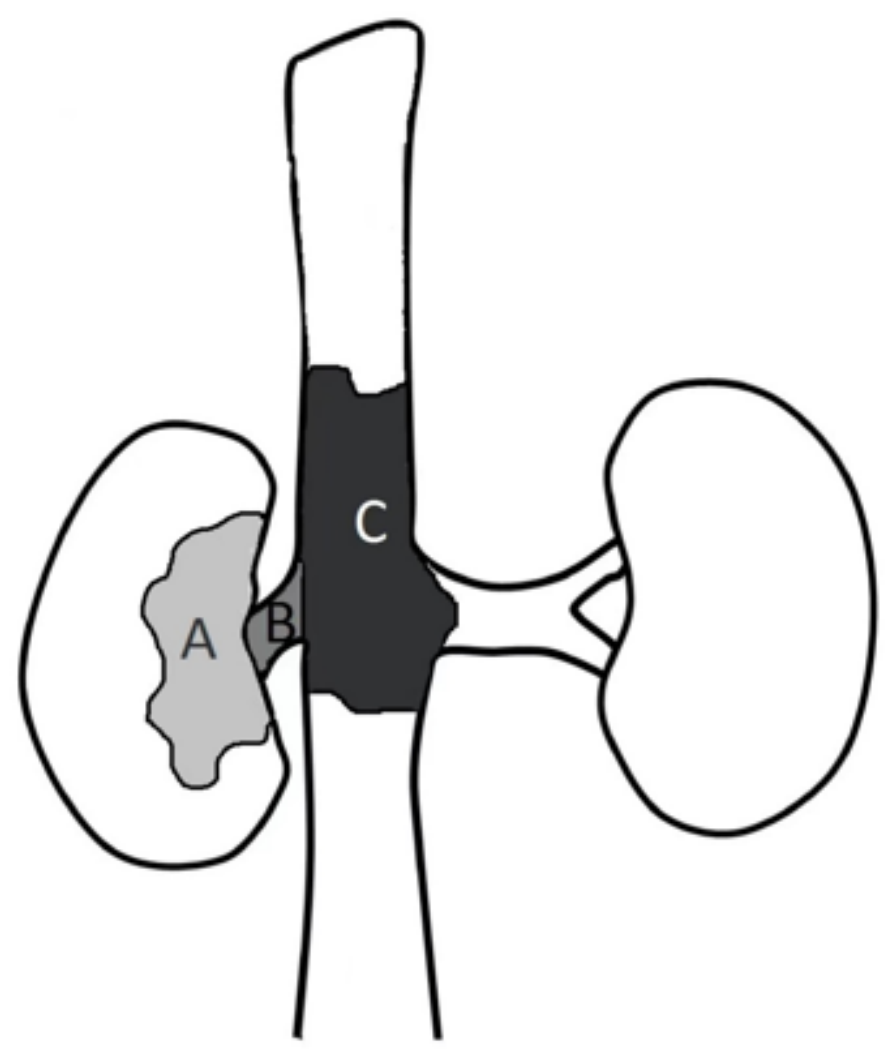

Figure 2

Tumor volume was classified into groups. The volume for renal cell carcinoma, renal vein thrombus, inferior vena cava thrombus, total thrombi volume, and total tumor volume is labeled as $A, B, C, D$ $(D=B+C)$, and $E(A+B+C)$, respectively. 

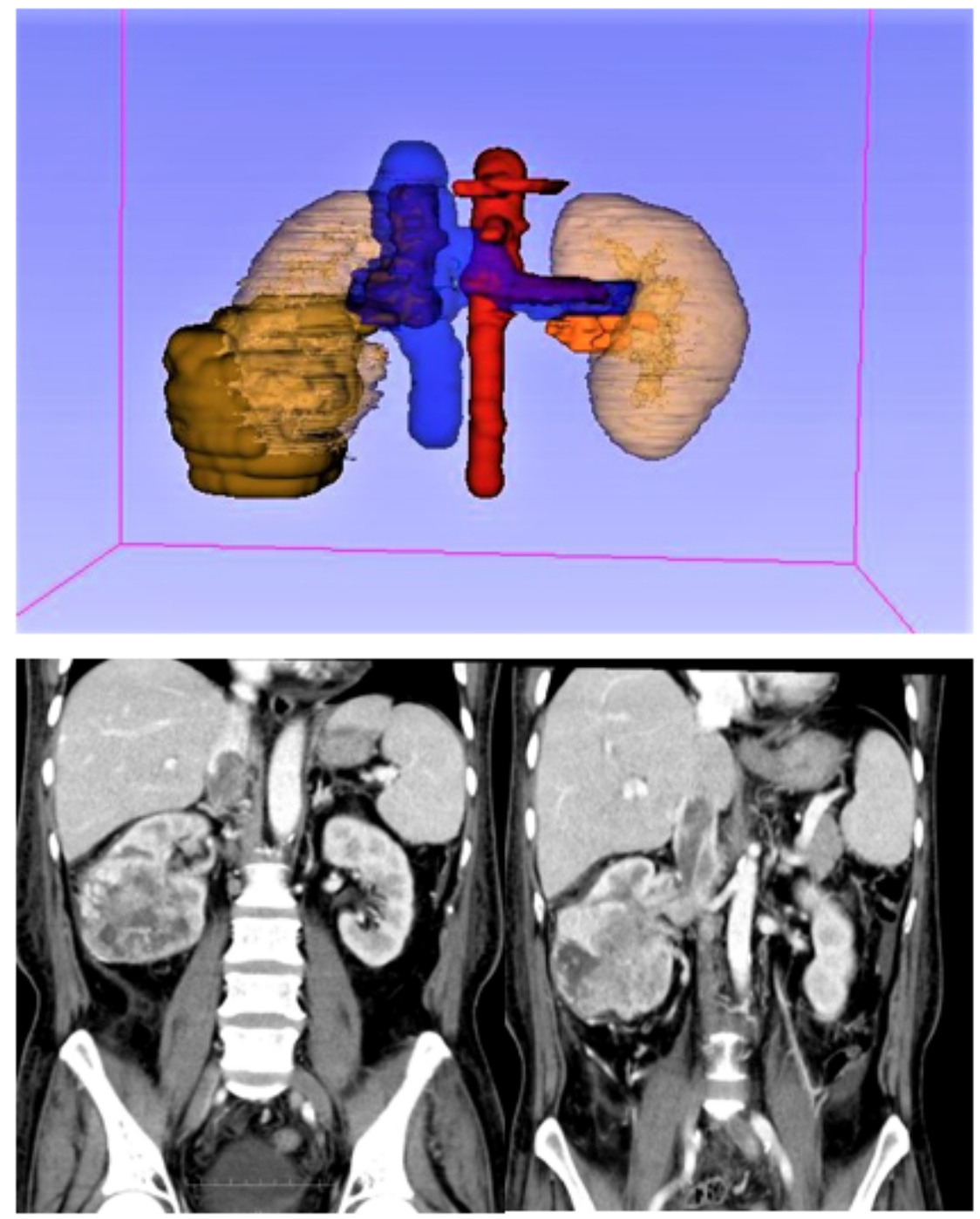

Figure 3

A 3D model of a 53 years old Chinese male patient created by 3D Slicer. The patient was diagnosed with right renal cell carcinoma invading the venous system. RCC, RVT, and IVCT volume calculated for this patient are $351.03 \mathrm{~cm} 3,11.86 \mathrm{~cm} 3$, and $48.79 \mathrm{~cm} 3$, respectively. The patient underwent open approach surgery on 24th June 2019. Total operative time and Intra-operative blood loss for this patient were 359 minutes and $2000 \mathrm{ml}$, respectively. On his most recent follow-up in Jan 2020, the patient was alive, however abdominal CT showed peritoneal and liver metastases. 

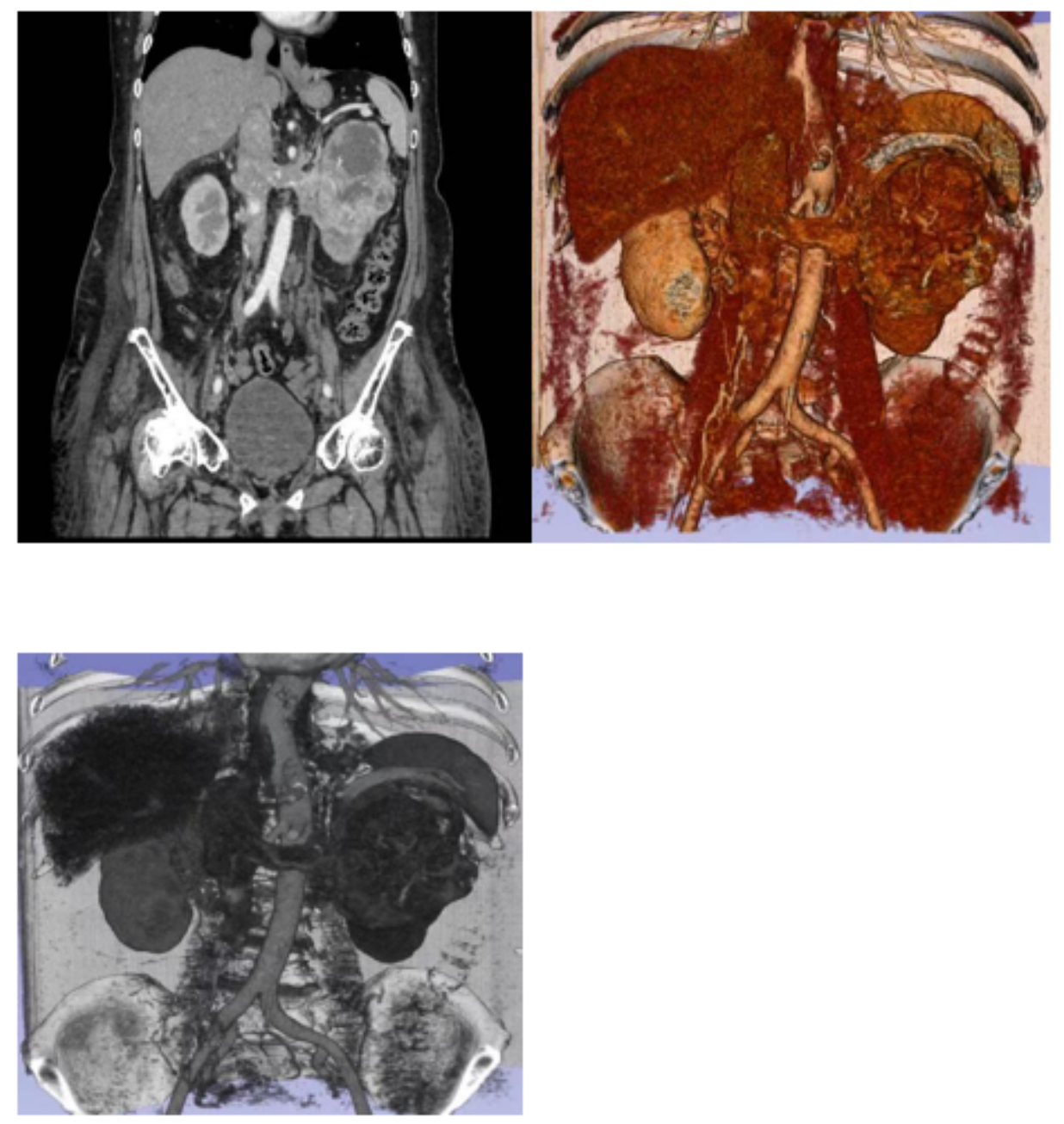

\section{Figure 4}

A different version of 3D image made with 3D Slicer for a left-sided RCC invading the venous system (Mayo grade II) patient who underwent surgical treatment in PKUTH. In this version, only two colors are available. 